\title{
Gallbladder Perforation with Postoperative Preservation of Peritoneal Dialysis Catheter
}

\author{
Anna Silda, Viktorija Kuzema, Ilze Puide, Harijs Čerņevskis, Aivars Pētersons \\ Nephrology Department, Pauls Stradins Clinical University Hospital, Riga, Latvia
}

Received: 06/01/2016

Accepted: $17 / 01 / 2016$

Published: 03/03/2016

How to cite this article: Silda A, Kuzema V, Puide I, Čerņevskis H, Pētersons A. Gallbladder perforation with postoperative preservation of peritoneal dialysis catheter. EJCRIM 2016;3:doi:10.12890/2016_000378

Conflicts of Interests: The authors declare that there are no competing interests.

This article is licensed under a Commons Attribution Non-Commercial 4.0 License

\section{ABSTRACT}

A patient undergoing peritoneal dialysis was admitted with acute peritoneal dialysis-related peritonitis. On the 10 th day of intraperitoneal antibacterial therapy, the patient's dialysate developed a green color. Gallbladder perforation was revealed. The patient underwent a conventional cholecystectomy with a preserved peritoneal catheter. There are few cases in the medical literature about green dialysate. In all of them, peritoneal dialysis catheters were removed after cholecystectomy. The present case report shows a patient with an intact peritoneal catheter and with no further complications.

\section{LEARNING POINTS}

- Bilirubin measurement in a dialysate helps to differentiate gallbladder perforation from other causes of peritonitis.

- Urgent diagnostics and treatment is required in patients with changes in dialysate colour.

- Preservation of perithoneal catheter can be considered after a laparotomy.

\section{KEYWORDS}

Cholecystitis; gallbladder perforation; green dialysate; peritoneal catheter; peritoneal dialysis.

\section{INTRODUCTION}

Perforation of the gallbladder represents a rare life-threatening complication of cholecystitis. The incidence of clinical symptoms is variable and may be absent in chronic or subacute progression of disease ${ }^{[1]}$, as well as in the elderly and patients with diabetes and peritoneal dialysis. The Authors report the case of an elderly patient on continuous ambulatory peritoneal dialysis (CAPD) and gallbladder perforation.

\section{CASE REPORT}

An 81-year-old active man, a former professional athlete, was admitted to hospital with complaints of shortness of breath and fatigue. At the time of admission, his dialysate had allegedly been cloudy for two days. The patient had end-stage renal disease, due to chronic interstitial nephritis, and had been undergoing peritoneal dialysis (PD) in a CAPD regimen for three years. During this period, he was admitted to hospital twice: once due to a peritoneal catheter exit-site infection with Klebsiella oxytoca (last time in 2012) and the second time with erysipelas (2011).

Regarding the present case, the patient presented with diffuse pulmonary crackles, tachycardia, fatigue, minimal abdominal discomfort, and muscle weakness. The diagnosis of acute CAPD peritonitis was confirmed by clinical and bacteriological dialysate testing. Escherichia coli, 
which is sensitive to ceftriaxone and gentamicin, had grown in the dialysate culture. Antibacterial intraperitoneal therapy with ceftriaxone and vancomycin was started. Positive dynamics of the overall condition and leukocyte number in the dialysate were noted. Hypotension and muscle weakness remained unfavorable factors. On the 10th day of admission, the patient developed vomiting in the afternoon and a change in dialysate color to green in the evening. The fasting dialysate was greener than the non-fasting dialysate (Fig. 1).

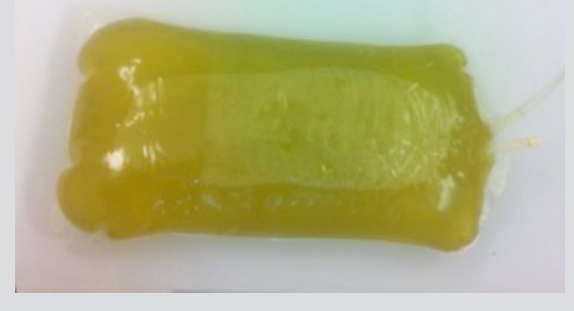

Figure 1: Green dialysate.

The patient neither lacked appetite nor had a fever or abdominal pain. The physical examination was negative for peritoneal irritation symptoms. A computed tomography (CT) was performed, which revealed gallstones and a thickened, uneven, gallbladder wall that could not be screened over the entire length. There was elevated alkaline phosphatase in blood biochemistry - 191 U/I (N=45-129), normal bilirubin, alanine aminotransferase (ALT), and aspartate aminotransferase (AST).The bilirubin measured in the afternoon dialysate was $1 \mathrm{mkmol} / \mathrm{l}$. A laparotomy was performed revealing a few micro-abscesses, as well as micro-perforations in the gallbladder posterior wall. Despite the nephrologist's advice to remove the peritoneal catheter during surgery, the patient underwent a conventional cholecystectomy with the peritoneal catheter intact.

Histological conclusion of surgical material: the patient suffered from phlegmonous cholecystitis with ulcerous mucosal lesions in the setting of chronic calculous cholecystitis. The patient was switched to hemodialysis, and over the first two weeks following surgery received ceftazidime intraperitoneally during the night. Then, he returned to peritoneal dialysis: first, two weeks on automatized peritoneal dialysis (APD), then on CAPD. After 38 days of hospitalization, he was discharged in good condition. No peritonitis was observed over the following two months.

\section{DISCUSSION}

Dialysis could be a risk factor for cholelithiasis. Gallstone disease is detected in $28 \%$ of patients on regular dialysis treatments ${ }^{[2]}$. Peritoneal dialysis patients have a higher mortality rate after developing acute cholecystitis ${ }^{[3]}$. There are several cases in the medical literature of gallbladder perforation in a patient on peritoneal dialysis ${ }^{[4-7]}$. The first reported case was described in 1996 , and it was associated with Klebsiella oxytoca peritonitis ${ }^{[4]}$. Two cases reported asymptomatic perforation and the following green dialysate were published in 2006 and 2012 in a 53-year-old type 1 diabetes patient ${ }^{[5]}$ and an 81-year-old woman ${ }^{[6]}$, both on CAPD. Yi-Teng C. et al describe an 80-year-old man with symptomatic gallbladder perforation ${ }^{[7]}$. In all of these cases, peritoneal dialysis catheters were removed after cholecystectomy, and patients were switched to hemodialysis for one month or more. The present case report shows a patient with an intact peritoneal catheter, who restarted peritoneal dialysis in the 2 weeks after surgery, and an overall favorable outcome. We do not recommend preserving peritoneal dialysis catheter after a laparotomy, but it can be considered as an option in further clinical practice.

\section{REFERENCES}

1. Gobel T, Kubitz R, Blondin D, Haussinger D. Intrahepatic type II gall bladder perforation by a gall stone an a CAPD patient. Eur J Med Res 2011:16:213-216.

2. Badalamenti S, DeFazio C, Castelnovo C, Sangiovanni A, Como G, De Vecchi A, et al. High prevalence of silent gallstone disease in dialysis patients. Nephron 1994;66:225-7.

3. Chen YT, Ou SM, Chao PW, Li SY, Chen TJ et al. Acute cholecystitis in end-stage renal disease patients: a nation-wide longitudinal study. Dig Liver Dis 2013;45:142-6.

4. Geddes CC, Waterson A, Asari A, Smith WG. Perforation of the gallbladder in a patient on continuous ambulatory peritoneal dialysis. Nephrol Dial Transplant 1996;11:24932494.

5. Babin J, Langlois S, Friede J, Guay G, Agharazii M. Green dialysate: asymptomatic perforated cholecystitis without peritonitis. Nephrol Dial Transplant 2006;21:1121-2.

6. Chia-Ter C, Jeng-Wen H. Asymptomatic green dialysate. Am J Med Sci 2012;344:227.

7. Yi-Teng C, Chun-Chieh H, Chin-Chi K, Huey-Wen C, Ming-Shiou W. Green dialysate. Kidney Int 2010;77:369. 